\title{
Case report: paroxysmal cold hemoglobinuria presenting during pregnancy
}

\author{
Andrea O Akpoguma, Thomas L Carlisle and Steven R Lentz
}

\begin{abstract}
Background: Paroxysmal cold hemoglobinuria is caused by a biphasic $\lg G$ autoantibody that triggers complement-mediated intravascular hemolysis. Paroxysmal cold hemoglobinuria has not previously been reported to occur in association with pregnancy.
\end{abstract}

Case presentation: We report a case of an 18 year old female who presented in early pregnancy with acute hemolytic anemia and a positive Donath-Landsteiner antibody test. She was diagnosed with paroxysmal cold hemoglobinuria and treated supportively. Her hemolysis resolved within 6 weeks. Because maternal lgG autoantibodies can cross the placenta, the patient was monitored closely throughout her pregnancy for recurrence. The outcome of the pregnancy was successful, with no evidence of neonatal anemia or hemolysis.

Conclusion: This patient had a classic presentation of paroxysmal cold hemoglobinuria with rapid onset of hemolytic anemia that resolved spontaneously. To our knowledge, this is the first report of paroxysmal cold hemoglobinuria presenting during pregnancy.

Keywords: Donath-Landsteiner antibody, Paroxysmal cold hemoglobinuria, Pregnancy, Hemolytic anemia

\section{Background}

Paroxysmal cold hemoglobinuria $(\mathrm{PCH})$ is a rare form of autoimmune hemolytic anemia mediated by a biphasic IgG autoantibody that triggers complement-mediated intravascular hemolysis. The name $\mathrm{PCH}$ is derived from its classic presentation with episodic hemoglobinuria, typically following exposure to cold temperature. First described by Donath and Landsteiner 1904 [1-4], PCH was once considered to be a chronic condition in adults due to its association with syphilis. Today, most cases of $\mathrm{PCH}$ are acute, self-limited disorders that occur following transient viral or bacterial infections in children or adults [1-5]. Post-infectious PCH is usually caused by a polyclonal IgG autoantibody with specificity for the erythrocyte P antigen [1-3,5-11]. PCH also can present in association with lymphoproliferative disorders, in which case the pathogenic autoantibody tends to be a monoclonal IgG $[9,10]$. To our knowledge, PCH associated with pregnancy has not been described previously. Herein, we report a case of a young, healthy female who

\footnotetext{
* Correspondence: steven-lentz@uiowa.edu

Department of Internal Medicine, University of lowa Carver College of
} Medicine, lowa City, IA, USA presented during early pregnancy with acute intravascular hemolysis due to $\mathrm{PCH}$.

\section{Case presentation}

An 18 year old female patient presented with acute symptoms of abdominal and flank pain, nausea, dark red urine, fevers and chills. One month prior to presentation, she had experienced a few days of rhinorrhea and headaches, suggestive of a viral upper respiratory tract infection. Upon presentation, she was found to be pregnant by serum hCG and ultrasound, with an estimated gestational age of 6 weeks. Laboratory evaluation showed hemoglobin $11.2 \mathrm{~g} / \mathrm{dL}$, haptoglobin $<20 \mathrm{mg} / \mathrm{dL}$, total bilirubin $6.8 \mathrm{mg} / \mathrm{dL}$, direct bilirubin $0.7 \mathrm{mg} / \mathrm{dL}$, lactic acid dehydrogenase (LDH) $735 \mathrm{U} / \mathrm{L}$, and absolute reticulocyte count $49.3 \mathrm{~K} / \mu \mathrm{L}$. Urine analysis demonstrated $3+$ blood and the microscopic examination was negative for red blood cells. A direct antiglobulin test was positive for anti-C3d and negative for IgG. The cold agglutinin titer was negative $(<2)$. Donath Landsteiner antibody testing was performed using a blood sample that was immediately immersed into an insulated container filled with water at $37^{\circ} \mathrm{C}$, and directly delivered to the testing laboratory. A Donath Landsteiner antibody test was 
positive (Figure 1), confirming the diagnosis of $\mathrm{PCH}$. Over the next 48 hours, the patient's hemoglobin declined to $7.3 \mathrm{~g} / \mathrm{dL}$ (Figure 2). She was managed supportively with a prenatal vitamin supplement and encouraged to keep warm. Her hemoglobin and LDH normalized by day 42 (Figure 2). A Donath Landsteiner test on day 77 was negative. Her hemoglobin declined during the third trimester of pregnancy, to $11.0 \mathrm{~g} / \mathrm{dL}$ on the day of delivery, without any laboratory evidence of recurrent hemolysis. She delivered a healthy female child by Cesarian section at 39 weeks of gestation. The neonate did not have anemia or hemolysis after birth.

\section{Conclusions}

$\mathrm{PCH}$ was initially described in the late $1800 \mathrm{~s}$ as a syphilis-associated chronic relapsing condition triggered by cold exposure [1-5]. Today, most cases of $\mathrm{PCH}$ are characterized by acute episodic hemolytic anemia that is transient and self-limited, although some cases of chronic or recurrent non-syphilitic $\mathrm{PCH}$ have been reported $[1-3,5,11,12]$. $\mathrm{PCH}$ is more common in children than adults, and often presents 1-2 weeks after a respiratory tract infection $[1,3,5-8,11]$. Severe and rapidly progressive anemia occurs, often (as in the case reported

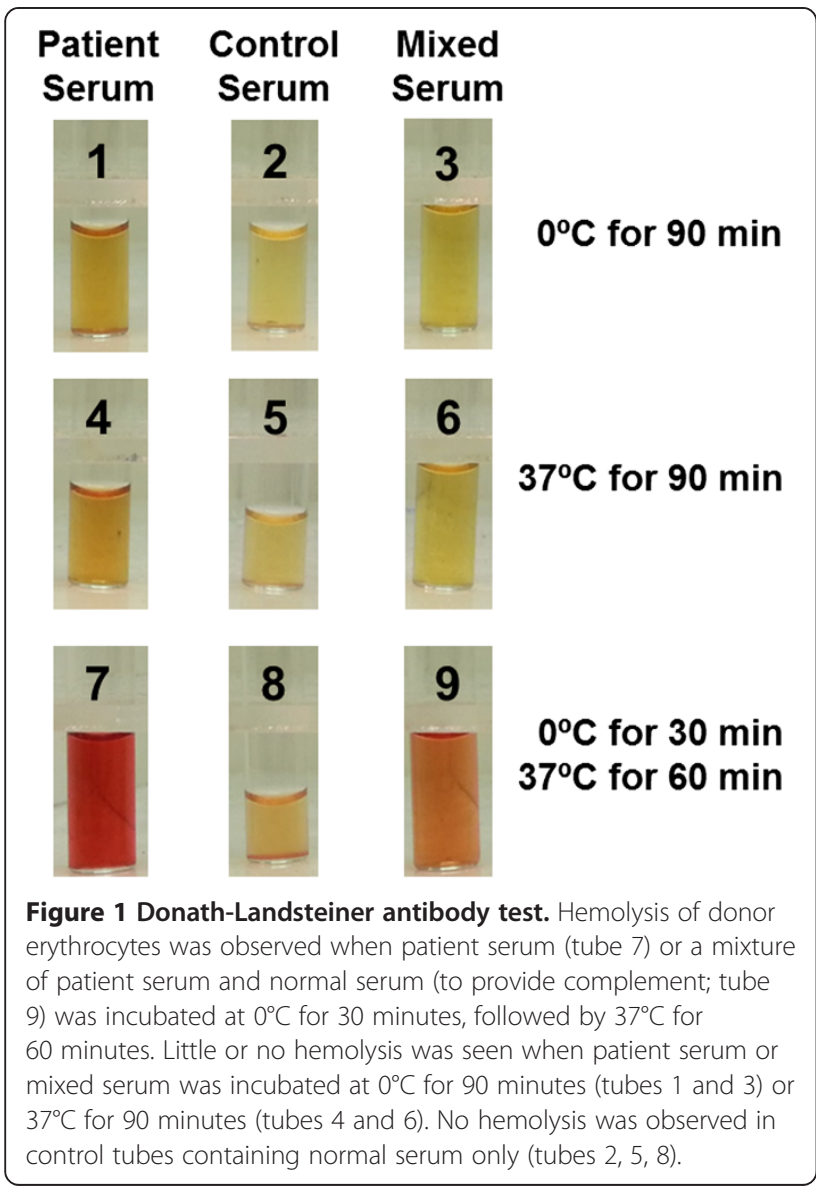

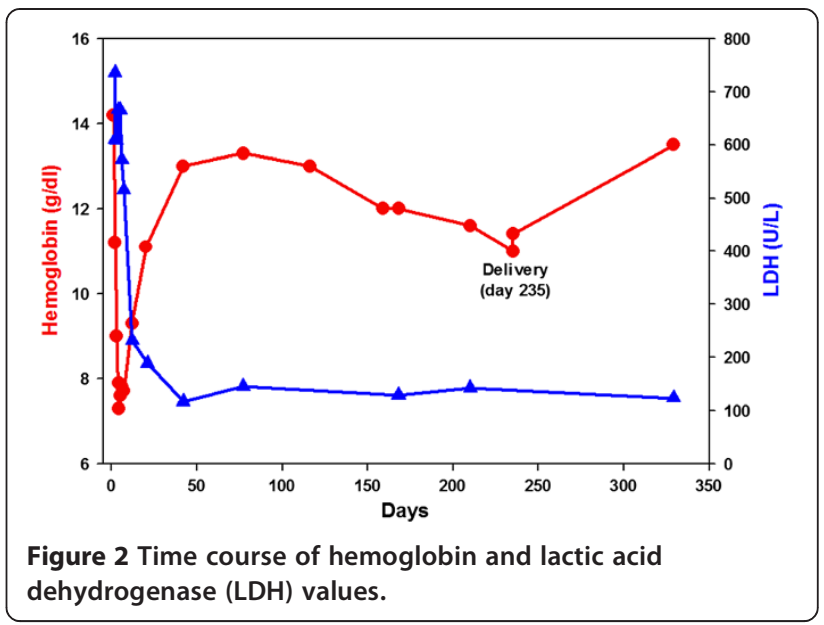

here) with a relative reticulocytopenia. The reticulocytopenia is thought to represent an ineffective bone marrow response either due to marrow suppression from viral infection or other causes $[5,6,10]$. Although acute episodes of hemolysis are frequently severe, $\mathrm{PCH}$ typically resolves spontaneously within a few days to weeks after onset. Treatment is generally supportive and consists of blood transfusions, intravenous fluids, and warming. Therapy is directed towards treating symptoms of anemia and preventing end organ complications from intravascular hemolysis. Treatment with corticosteroids and rituximab has been reported, but the value of these therapies is uncertain due to the usually transient nature of the hemolysis.

The pathogenic Donath Landsteiner autoantibody was first described in 1904 as a biphasic hemolysin that binds to red blood cells only at low temperatures and, upon warming, induces compliment activation and lysis $[2,3]$. In contrast to autoimmune hemolytic anemia mediated by IgM cold agglutinins, most cases of $\mathrm{PCH}$ are caused by non-agglutinating IgG antibodies with anti-P specificity $[2,3,8]$. The Donath Landsteiner antibody usually appears 1 week after the onset of illness and can persist from 1 to 3 months [8]. To avoid pre-analytic error in Donath Landsteiner testing, it is important to maintain the blood sample at $37^{\circ} \mathrm{C}$ until serum is separated from cells in the laboratory. This prevents adsorption of anti-P antibodies onto autologous red blood cells at low temperatures. Donath Landsteiner testing requires coordination between the clinical and laboratory teams to ensure appropriate sample collection, delivery, and testing.

The patient reported here presented in early pregnancy with acute hemolytic anemia, a negative cold agglutinin titer, and a positive Donath Landsteiner antibody test. We are not aware of a reported association between pregnancy and $\mathrm{PCH}$, but other forms of autoimmune hemolytic anemia have been reported to occur 
more frequently among pregnant than non-pregnant women $[13,14]$. It is possible that the development of the Donath Landsteiner antibody in this patient was unrelated to her pregnancy, especially since she reported symptoms of an upper respiratory infection one month prior to presentation. The patient had a classic presentation with rapid onset of hemolytic anemia that resolved spontaneously. Because maternal IgG autoantibodies can cross the placenta, the patient was monitored closely throughout her pregnancy for recurrence of $\mathrm{PCH}$. Donath-Landsteiner antibody testing became negative at 3 months and her hemoglobin improved to near baseline levels. She underwent an uncomplicated surgical delivery of a healthy infant who did not have any evidence of anemia or hemolysis.

\section{Consent}

Written informed consent was obtained from the patient for publication of this case report and any accompanying images. A copy of the written consent is available for review by the Editor of this journal.

\section{Abbreviations \\ PCH: Paroxysmal cold hemoglobinuria; LDH: Lactic acid dehydrogenase.}

\section{Competing interests}

The authors declare that they have no competing interests.

\section{Authors' contributions}

AOA, TLC, and SRL analyzed and interpreted the data. AOA and SRL wrote and revised the manuscript. All authors read and approved the final manuscript.

Received: 3 September 2014 Accepted: 30 January 2015

Published online: 13 February 2015

\section{References}

1. Bass GF, Tuscano ET, Tuscano JM. Diagnosis and classification of autoimmune hemolytic anemia. Autoimmun Rev. 2014;13(4-5):560-4.

2. Sokol RJ, Booker DJ, Stamps R. Paroxysmal cold hemoglobinuria and the elusive Donath-Landsteiner antibody. Immunohematology. 1998;14(3):109-12.

3. Sokol RJ, Hewitt S. Autoimmune hemolysis: a critical review. Crit Rev Oncol Hematol. 1985:4(2):125-54.

4. Sokol RJ, Hewitt S, Booker DJ. Erythrocyte autoantibodies, autoimmune haemolysis, and myelodysplastic syndromes. J Clin Pathol. 1989;42(10):1088-91.

5. Sanford KW, Roseff SD. Detection and significance of Donath-Landsteiner antibodies in a 5-year-old female presenting with hemolytic anemia. Lab Medicine. 2010:41(4):209-12.

6. Gunawardena D, Velu M, Senaviratne SN. Case report on a child with paroxysmal cold haemoglobinuria. Indian J Hematol Blood Transfus. 2012;28(2):112-3.

7. Hayashi H, Yasutomi M, Hayashi T, Yuasa M, Kawakita A, Hata I, et al. Paroxysmal cold hemoglobinuria caused by an IgM-class Donath-Landsteiner antibody. Pediatr Int. 2013;55(5):664-6.

8. Petz LD. Cold antibody autoimmune hemolytic anemias. Blood Rev. 2008:22(1):1-15

9. Sivakumaran M, Murphy PT, Booker DJ, Wood JK, Stamps R, Sokol RJ. Paroxysmal cold haemoglobinuria caused by non-Hodgkin's lymphoma. Brit J Haematol. 1999;105(1):278-9.

10. Stefanizzi C, Breccia M, Santopietro M, Coluzzi S, Cannella L, Girelli G, et al. Unusual association of paroxysmal cold hemoglobinuria as the first sign of disease in myelodysplastic patient. Int J Hematol. 2009:89(5):720-1.

11. Taylor CJ, Neilson JR, Chandra D, Ibrahim Z. Recurrent paroxysmal cold haemoglobinuria in a 3-year-old child: a case report. Transfus Med. 2003;13(5):319-21.
12. Koppel A, Lim S, Osby M, Garratty G, Goldfinger D. Rituximab as successful therapy in a patient with refractory paroxysmal cold hemoglobinuria. Transfusion. 2007;47(10):1902-4.

13. Hoftman AC, Hernandez MI, Lee KW, Stiehm ER. Newborn illnesses caused by transplacental antibodies. Adv Pediatr. 2008;55:271-304.

14. Dhingra S, Wiener JJ, Jackson H. Management of cold agglutinin immune hemolytic anemia in pregnancy. Obstet Gynecol. 2007;110(2 Pt 2):485-6.

\section{Submit your next manuscript to BioMed Central and take full advantage of:}

- Convenient online submission

- Thorough peer review

- No space constraints or color figure charges

- Immediate publication on acceptance

- Inclusion in PubMed, CAS, Scopus and Google Scholar

- Research which is freely available for redistribution 